April - 2003

\title{
Bridges to Effective Learning through Radio
}

\author{
Usha Chandar and Ramesh Sharma \\ Indira Gandhi National Open University \\ India
}

\begin{abstract}
Indira Gandhi National Open University has been allotted 40 FM radio stations from which to broadcast educational programmes for the benefit of students and general public in India. These FM radio stations, delivered through the Gyan Vani network, cater to learners seeking to gain knowledge in the areas of basic, primary, higher, and extension education. Radio programming covers various subject areas. It is anticipated that the opening of India's airwaves will prove beneficial to the nation's general population, thus fostering the democratising principals of empowerment, advocacy, and community participation. This study examines the results of a survey conducted to obtain feedback from a representative sample of the Gyan Vani network's projected audience. The survey focused on audience's perceived need for a radio channel dedicated exclusively to educational programming; it also provided an opportunity for respondents to suggest possible programme content and formats. Respondents, in general, indicated that they looked towards the network Gyan Vani to fulfil personal and educational goals by offering certified vocational courses, coaching for entrance exams, updated information on careers, courses, etc.
\end{abstract}

Keywords: Gyan Vani; radio for education; India; survey

\section{Introduction}

The establishment of the Indira Ghandi National Open University (IGNOU) in 1985 was an important milestone in India's educational history. Through the use of open and distance modalities, IGNOU currently provides an array of educational options to those desiring to improve their qualifications and upgrade their academic skills. By design, IGNOU establishes a direct bridge between education and vocation, thus extending the scope and reach of higher education to underprivileged groups and individuals, many of whom reside in India's remote and rural areas.

IGNOU's mandate is to provide higher educational opportunities to one and all, a principle that acts to democratise higher education in India. In its effort to provide student support services and to deliver open and distance programmes, IGNOU has developed a diversified delivery system comprising a vast physical network of regional study centres. Reflecting differences in the needs of learners and the didactic nature of the programmes, different types of study centres have been developed. IGNOU's institutional network is further augmented through the use of such electronic media and computer networks as: radio, television, cable TV, audio/video cassettes, CD-ROMs, Internet, interactive systems (one-way-video/ two-way-audio teleconferencing) and 
interactive radio counselling. In this educational mix, radio is an important medium that helps support students studying at a distance, as well as those generally interested in expanding their knowledge.

\section{Radio for Education}

Radio has been used in different formats for educational purposes the world round. Radio technology was first developed during the late nineteenth century and came into popularity as an educational medium during the early twentieth century. Although often overshadowed as educational medium vis-à-vis other technologies such as television, radio remains a viable medium that has proven educational worth in terms of both pedagogical importance and geographical reach. Radio is capable of delivering high quality educational programming to highly diversified audiences located across broad geographical expanses - all at a low per unit production cost (Couch, 1997). Studies conducted by the Open University UK have demonstrated that, when used as a supplementary learning tool, radio benefits weaker students (Tripp and Roby, 1996). The Agency for International Development has shown radio to be more costeffective and capable of exerting greater learning effects than textbooks or teacher education (Tripp and Roby, 1996). Radio has the advantage of permitting the teaching of subjects in which classroom teachers are untrained or lacking certain knowledge sets. Another benefit for multigrade classroom use is that radio can provide instruction for one group of students, whilst the teacher is occupied with another. Radio can also bring new or previously unavailable resources into the classroom, thereby greatly enhancing student learning (Muller, 1985). As a medium that can be listen to in the privacy of one's home or room, radio is often the preferred choice for those seeking information on culturally taboo topics such as HIV/AIDS or STDs.

Jaminson and McAnany (1978) report three main advantages of radio: (1) improved educational quality and relevance; (2) lowered per student educational costs; and (3) improved access to education, particularly for disadvantaged groups. Some limitations of radio for educational purposes are that it inherently lacks interaction; instructor feedback and clarification are generally unavailable; instruction cannot be interrupted or reviewed by students (unless it is tape-recorded); the pace of the lesson is fixed; note taking is difficult for some; and time for reflection is minimal. To overcome these drawbacks, preparation, supporting materials, and follow-up exercises are recommended when possible (McIsaac and Gunawardena, 1996). Below are a few points made by the many academics that have researched the use of radio for educational purposes:

- Byram, Kaute, and Matenge (1980) reported on the use of radio for civics education in Botswana.

- Muhlmann de Masoner, Masoner, and Bernal (1982) described the use of radio in Columbia for various educational subjects.

- Ray (1978) revealed radio as effective in promoting improvements in farming practices and production in Guatemala.

- Long (1984) reported the use of radio in India for rural development.

- Kinyanjui (1973) found radio to be a supportive medium in Kenya correspondence courses.

- Ouane (1982) described use of radio in Mali for literacy training. 
- Ginsburg and Arias-Goding (1984) examined use of radio for literacy training and other programs in Mexico.

- Cooke and Romweber (1977) found radio was used in Nicaragua for health education.

- In Nigeria, Shears (1984) reported radio being used for management courses in the agriculture sector.

- Academy for Educational Development (1979) described radio being used in Paraguay to offer primary school instruction.

- Cooke and Romweber (1977) reported adoption of radio in the Philippines for nutrition education.

- Park (1967) reported radio in support of family planning in South Korea.

- Academy for Educational Development (1980) reported use of radio in Sri Lanka to promote family planning and health education.

- Byram and Kidd (1983) reported using radio for public health purposes in Swaziland.

- Galda (1984) reported use of radio in Thailand to teach mathematics to school children and Faulder (1984) reported its use for teacher training and other curricula.

- White (1976) reported adoption of radio in the Dominion Republic to support primary education.

- Saettler (1990) revealed that the University of Wisconsin and the University of Minnesota received licenses to establish educational radio stations in 1922.

- Gueri, Jutsun, and White (1978) reported use of radio in Trinidad and Tobago to promote knowledge of breastfeeding.

\section{Radio for Educational Purposes in India}

Vyas, Sharma and Kumar (2002) reported some major educational radio projects in India:

- The School Broadcast Project was commissioned in 1937 to focus on elementary school students.

- Adult education and community development project (Radio Forum: 1956), served residents of 144 villages in the vicinity of Poona, Maharastra state, which were the main beneficiaries.

- Farm and Home Broadcast Project, which commenced operation in 1966, targeted farmers and those living in rural towns and villages.

- University broadcast project, launched in 1965, targeted university students.

- Language Learning Programme, launched in 1979-80, provided instruction in Hindi as a first language to school aged children. 
- IGNOU-AIR (All India Radio) was launched in January 1992 in collaboration with IGNOU, AIR stations of Mumbai, Hyderabad and Shillong. IGNOU-AIR broadcasts IGNOU educational programmes to serve students enrolled in both open and conventional universities.

- IGNOU-AIR Interactive Radio Counselling, launched in 1998, targets university students enrolled in both conventional and open programmes of study.

- Gyan-Vani, India's first exclusive educational FM radio network, was launched in 2001 to serve a target audience of university students enrolled in both conventional and open programmes of study.

Vyas, Sharma and Kumar (2002) also reported on an experiment of radio-vision technique (Multimedia through Digital Radio) carried out in 1975-76, by India's National Council of Education Training and Research as one of its multi-media components for inservice teacher training purposes.

In their evaluative study focusing on interactive radio, Bansal and Choudhary (1999) reported that radio holds great potential in terms of supporting students who are learning at a distance. The first course of study to use interactive radio as a mode of distance education delivery was a radio project targeting students enrolled in IGNOU's Management and Bachelor Preparatory Programme. Students enrolled in this pioneering effort reported that the interactive radio sessions proved effective in helping them achieve their coursework objectives. Students enrolled with other institutions and the general public also participated in these interactive radio sessions; these two groups reported interactive radio as an 'interesting experience.' Significantly, the Management and Bachelor Preparatory Programme students also registered a higher rate of participation using interactive radio, than during teleconferences and even face-to-face sessions.

Karim, Kama, and Islam (2001), investigated the role of radio and TV programmes used in distance open learning system at the Bangladesh Open University. They reported radio and TV programmes guide learners on how to use the courses, and offer adequate explanations of concepts.

Sukumar (2001) undertook a study of interactive radio counselling as practiced in IGNOU. He found that radio counselling provides an excellent opportunity for learners in remote areas to raise concerns, ask questions, and generally interact directly with teachers/ speakers. Interactive radio counselling also provides an opportunity for the general public to connect with speakers, thus adding a new and enriching dimension to the general publics' learning experiences. Sukumar's study also revealed listeners considered radio counselling as both popular and effective.

Times News Network (2003) reported the finding of a study conducted by A. C. Nielsen, called the Radio Audience Measurement (RAM). The RAM measured radio listener-ship ratings in Mumbai (India), which found that since the launch of private FM radio in India, the number of people tuning into radio has increased steadily. An earlier report of RAM (June, 2002) indicated that nearly 42 per cent of Mumbai's population tuned into to FM radio. RAM's current report (2003) shows that 72 per cent of the population of the area now listen to FM radio stations. The report surveyed over 2000 listeners using the "Day After Recall Method.” In sum, the RAM study revealed that listeners regard FM radio as an increasingly popular medium. 
India's government has allotted certain frequencies in the popular FM band for educational purposes. The anticipated results are that the increased availability of knowledge and information will reach and benefit all sectors of Indian society - including illiterate populations. With UNESCO support, IGNOU conducted an experiment in 2001 that led to the evolution of the concept of 'Radio-Vision' or 'Home School.' The multi-site, multi-partner pilot experiment explored innovative applications of satellite based digital radio broadcasting systems (Asia Star of WorldSpace) primarily for distance learning purposes. A feasibility study was thus designed and conducted using the same new satellite digital technology in distance learning. Sreedher (2002) reported successful transmission of such media in terms of hyper-linking and downloading multimedia courseware, conditions that lead to cost effective transmission and distribution of audio-visual courseware. Dikshit (2002) suggested using terrestrial FM radio transmitters in conjunction with satellite radio transponders to enable the global distribution of local content. For more details, please visit: http://www.ignou.ac.in/unesco/unesco46.htm.

Another use for FM radio (e.g., teaching tool) has been the recent introduction text data transfer technology delivered and received via computer networks (e.g., students' tool). In short, the introduction of this new technology creates a new radio/ text environment. The convergence of radio with computer technology now allows students to send and receive text messaging to the radio station, a dynamic which greatly enables and enhances student learning using low cost FM radio delivery technology. Chaudhary (1996) described an experiment using radio-text at Yashwant Rao Chavan Maharashtra Open University, Nasik, India. In his study, he revealed high satisfaction (more than 80 per cent) among learners using radio-text technology.

\section{Gyan Vani: Current realities and future direction}

The Gyan Vani educational FM radio network, which was launched in 2001, will eventually comprise of 40 Stations linking various cities and towns across India. Gyan Vani will broadcast approximately 43,800 hours of educational programming per year. Currently, six FM radio stations are now operating at Allahabad, Bangalore, Coimbatore, Lucknow, Vishakhapatanam, and Bhopal. Gyan Vani's radio network is slated to expand in phases, thus incrementally expanding its educational reach to all parts of the country.

Gyan Vani FM radio uses $10 \mathrm{Kw}$ stereophonic FM transmitters capable of emitting a broadcast footprint with a radius of about $60 \mathrm{Kms}$, enough to cover an entire city or town plus its surrounding suburbs. In terms of technology, FM radio stations are usually fully digital and operated by professionals. Representatives of educational organizations, colleges, training institutions, universities, professional institutions, NGOs, government, and quasi-governmental organizations are expected to contribute to the programming content of public radio, primarily in the form of pre-recorded programmes, or through participation in interactive radio sessions. Thus Gyan Vani radio FM is positioned as an ideal medium for fulfilling local educational, developmental, and socio-cultural aspirations and needs.

\section{Gyan Vani: A cooperative model}

Gyan Vani's mandate is to carve out an identity that is both unique and distinct from India's other radio broadcast interests. It achieves this employing a decentralized managerial approach and philosophy. Each station has been given a measure of autonomy; its programming and delivery of localized content is guided by a local steering committee consisting of different community stakeholders. Gyan Vani's central office assumes responsibility for policy planning, monitoring, 
budget, and administrative support. The suggested cooperative model envisages 60:40 programming ratio, a mix representing the following educational and social sectors:

- Serva Shikha Abhiyan

- Primary and Secondary Education

- Adult education

- Technical and vocational education

- Higher education

- Distance education

- Extension education

- Indian ministries such as Agriculture, Environment, Health, Women and Child Welfare, Science and Technology, etc.

- NGOs

- United Nation agencies

Each partner receives between one to two hours of broadcast time daily. Subsequent resource mapping and audience profile studies examining all 40 centres' broadcast needs will be undertaken with the help of established institutes and social sector stakeholders. Key stakeholders will collaboratively shoulder responsibility for periodic monitoring, reviewing, and evaluating content.

\section{Gyan Vani: Vision statement}

Gyan Vani's vision is to be an interactive, participatory, educational initiative that bridges the gap between those who are educationally privileged and those who are deprived (ERT Unit, 2001). Using radio as a medium to disseminate information and facilitate communication, Gyan Vani promotes the development of community values and establishment of a learning environment in Indian society. By facilitating the ideas and ideals of public participation, it seeks to empower India's people, particularly those who are disadvantaged. Its mission is to overcome the social burdens of illiteracy and other disadvantages in the learning domain through the use of modern interactive communication technologies. Ultimately, Gyan Vani strives to revive indigenous knowledge systems premised on rich oral traditions, culture and heritage. To achieve this objective, Gyan Vani will be building larger and nation-wide collaborations, whilst at the same time strengthening local level partnerships.

\section{How does Gyan Vani Differ from All India Radio (Air)?}

\section{How Does Gyan Vani'S content/programming differ from All India Radio (Air)?}

Gyan Vani will only broadcast relevant educational and information programmes, with the underlying goal of enhancing listener's specific knowledge sets.

\section{Does Gyan Vani reach different audiences?}

Although on a technical level, Gyan Vani can reach the same audience as AIR, it's programming content is strictly aimed at educating individuals interested in particular subjects or programmes of study. 
Chandar \& Sharma Bridges to Effective Learning through Radio

\section{Does Gyan Vani have goal or agenda different from Air?}

While AIR has a goal of education, entertainment, and information, Gyan Vani also has a goal of bringing interactive education into the homes of listeners.

\section{The Survey}

A survey was designed to obtain feedback from a representative sample of Gyan Vani's projected listening audience. Respondents were asked about their real or perceived need for a radio channel designated exclusively for education purposes. Respondents were also asked for suggestions about programming formats. The survey was conducted over a two-month period spanning May to June 2001, prior to the launch of the Gyan Vani station at Coimbatore. It must be noted that the study has limitations in terms of scope, sampling size, and details. However, the results may be considered suggestive of general trends.

A sample of 47 respondents was selected to avoid gender bias. Care was also taken to choose a sample that is representative of all learner- and socio-economic groups. The sample was limited and drawn from a geographic area within the radius in and around the Tamil Nadu Agricultural University campus at Coimbatore, the proposed site of Gyan Vani's first and main broadcast centre.

\section{Objectives}

The objectives of the present study were to:

- Analyse media consumption habits of viewers in relation to print media (e.g., newspaper), radio, and television

- Seek viewers' perceptions of the need for an exclusive educational radio channel

- Obtain viewers' opinions as to whether FM radio is an appropriate medium for Gyan Vani programming

- Ascertain what function radio holds in listeners' daily lives

- Determine aspects of viewers' lives that are influenced by radio programming

- Obtain listeners' suggestions relative to delivery formats for educational programming

- Obtain listeners' opinions on the most appropriate times for certain types of educational broadcast programming

- Seek suggestions for improvement of Gyan Vani programmes in terms of topics/ themes, presentation/ anchor style, levels of interactivity, and duration of programming, etc.

Technical Configuration of Gyan Vani at Coimbatore: Getting there from here . . . Gyan Vani shares the existing infrastructure of All India Radio (AIR), specifically the serial mast, antenna system, feeder line, and office space in the transmitting centre. An existing studio with a dedicated transmitter link is also shared with AIR. Since Gyan Vani was able to share and leverage AIR's existing infrastructure, the radio station was online sooner and at a lower cost than would have otherwise been possible. Nonetheless, some technology was procured separately. The new state-of-the art $10 \mathrm{kw}$ FM transmitter, with 40 individual 300 watt amplifiers, diplexer, and audio workstations used for Gyan Vani's broadcasts were purchased specifically for the network. Even if two or three amplifiers crash, the system will still broadcast signals at a strength of $1 \mathrm{Kw}$ to $10 \mathrm{Kw}$. In case of breakdowns or scheduled maintenance, this transmitter can be serviced 
simultaneously during broadcasts. "Diplexer” technology that links both AIRs and Gyan Vani's transmitters, ensure the two signals do not interfere with each other.

In terms of audio workspace, another partner institution's infrastructure, the GRD College of Science, was also leveraged and used. For programme linkage, specifically from audio workspace (GRD) to transmitter (AIR), a pair of non-exchange lines were procured from Bharat Sanchar Nigam Ltd., a state owned telephone agency. From the AIR studio to transmitter, AIR's existing studio to transmitter link is currently being used. However, from a technical standpoint, this choice is proving to be problematic on two fronts: (1) the technical quality of non exchange-lines are usually poor and tend to fail; (2) little spare capacity remains on AIR's current studio to transmitter connection, which means Gyan Vani's broadcasts are currently susceptible to breakdowns. To overcome such technical problems, an independent studio-to-transmitter is being planned for future installation.

Although Bharat Sanchar Nigam Ltd., the state owned telephone agency mentioned previously, has signed an agreement to provide the necessary bandwidth to Gyan Vani, it regrettably does not have enough high-level bandwidth capacity at this time to deliver the levels of interactivity Gyan Vani hopes to achieve. Indeed, Bharat Sanchar Nigam Ltd., whose overall service is reportedly poor, has yet to provide other basic services such as hotline telephone links. Due to these infrastructure constraints, Gyan Vani's current broadcast quality is poor, and as such listeners can only receive mono-mode FM signals at this time. And although ISDN technology to increase bandwidth is being investigated, a temporary stopgap measure has been employed to continue Gyan Vani broadcasts in the interim. Currently, Gyan Vani uses a UHF link, telecommunication technology designed for such purposes as walkie-talkie type communication used by police, ambulances, etc. Although such technology is admittedly inferior, the fact remains that it does avoid such inconveniences as frequent travel to and from GDR to AIR, etc. Moreover, it is also the only currently available alternative if and when a programme link fails. To complicate matters, because there is no power backup (e.g., diesel generator) for Gyan Vani's transmitter at this time, power failures also interrupt programming.

AIR's staff are currently handling Gyan Vani's technical operations in addition to their regular AIR-related workload. As a result, monitoring of signals by AIR staff is not currently possible. IGNOU is, however, compensating AIR staff via the payment of rental and technical service fees. Thus, in simple terms, both technical and infrastructure continue to plague Gyan Vani, but temporary stopgap solutions are being implemented until more permanent ones become available.

\section{Methodology}

To collect relevant data, a questionnaire was developed by incorporating and measuring different variables as defined in Gyan Vani's objectives. Basic demographic information on the respondents was also elicited through the questionnaire.

\section{Survey Findings}

The findings are presented under three separate sections: (1) demographic profiles; (2) media consumption habits for print, radio and television; and (3) suggestions for improvement of Gyan Vani programming. 


\section{Demographic Characteristics}

The findings relate to respondents' gender, age, educational level, and monthly combined family income. The survey sample was fairly representative with respect to gender. Of the total of 47 respondents, 23 (49 per cent) were female, and 24 (51 per cent) were male. The majority (62 per cent) of respondents were youth between 13 and 21 years of age and enrolled in either senior secondary or higher education. Average monthly combined family income of those surveyed was below Rs.5000.

\section{Media Consumption}

Respondents were asked to indicate whether they subscribe or read newspapers, listen to radio, or watch television. They were also asked how frequently they 'consumed' such media. In the data analysed, there were overlaps indicating that many respondents consumed more than one media. About 83 per cent of the respondents reported consuming print media. Of total respondents, 37 (79 per cent) subscribed to newspapers. The remaining 10 respondents (21 per cent) reported that they did not subscribe to newspapers, but instead read them at shops and public places.

Respondents were asked about their radio-listening patterns. About 55 per cent of respondents surveyed reported that they were regular listeners of radio (26 respondents). This included 11 (23 per cent) respondents who listened up to half hour per day. Two respondents reported listening to radio up to one hour per day; four up to 1.5 hours per day; seven more than two hours per day; and two more than 8 hours per day. Eleven respondents (23 per cent) reported they listened to radio occasionally. The main reason cited for 'not listening' was that some owned no radio sets; whilst others listen only to news, music, or cricket commentary, during power cuts when other forms of electronic media were not available. Ten ( 21 per cent) respondents reported they were non-listeners, even though some owned radios. Twelve (26 per cent) respondents indicated that they preferred to listen to radio alone; however, of this group, some reported that they are forced to listen to radio with their family, usually because only one radio set was available in the household. A significant number of respondents (51 per cent) reported that they preferred listening to the radio with their family and friends.

When asked about their television viewing patterns, 89 per cent of respondents reported that they watch television. Forty-two respondents (89 per cent) indicated they watch television regularly; one did not own a television set; whilst four reported that they only watch television occasionally.

When asked about a radio station devoted to educational programming, the majority of respondents indicated approval, a finding that tends to support the need for such educational broadcast service. Some interesting figures emerged when respondents' opinions were sought regarding appropriateness of using FM radio technology for GyanVani broadcasts: only 34 per cent indicated a positive response. Nearly half of those surveyed did not in favour the use of FM radio; however, these respondents were unaware of the concept of FM radio. A significant number of respondents (e.g., those who had previously indicated that they were non-listeners) preferred to remain silent on the subject.

Generally, respondents viewed radio as a news source domestically (inside India), and foreign (outside India). Twenty-three per cent felt that radio helps them to relax and unwind, whereas 13 per cent indicated that radio was strictly used for leisure. Seventeen per cent said that radio helps them to concentrate on their studies or work. 
Respondents were asked to recall at least one aspect of their life that was influenced by radio. More than half (55 per cent) indicated bulletins on local issues such as railway arrivals and departures, and load shedding, as important information that directly influenced their lives. Nineteen per cent reported that radio improved their general knowledge, whilst 11 per cent indicated that it provided tips on good health. Radio also increased respondents' general awareness in terms of job or career opportunities, good agricultural practices, moral values, entrance examinations, etc.

Respondents were asked for their views about the most appropriate times for educational broadcasts. Although preferred listening times varied according to students' schedules, the evening slots clearly emerged as prime time for radio programming. And whilst the sample was primarily aimed at gathering information from youth and learner groups, older adult respondents were keen to voice their views and wanting to be heard. They reported having a passion for music and noted that FM radio is particularly suitable for such programming. They were also nostalgic about radio as a medium, many preferring to listen to radio news broadcasts. Other respondents indicated a preference for radio for educational content delivery. Clearly, radio must cater to the educational needs of all age groups including those starting new careers in mid-life, learning new skill or hobbies, or retirees.

\section{Suggestions Provided by Respondents on Various Aspects}

Respondents were asked to offer suggestions on Gyan Vani's educational programming. 'Discussion' was the most suggested form of programming (43 per cent), followed by 'quiz show' programming (40 per cent). Respondents also indicated their preference for 'lecture' and 'docu-drama/ edu-tainment' programming. Eleven respondents (23 per cent) did not offer suggestions.

When asked to suggest improvements to improve the Gyan Vani programming, the majority indicated a preference for general knowledge programming. However, such response can best be understood in terms of respondents' age vis-à-vis their response. Most respondents surveyed were in the career building stage of their lives, and thus indicated a desire for more general knowledge to help them prepare for work related competitions. Hence, there appeared to be an overriding preference for technical and vocational programming, information technology, and general science programming. Overall, respondents indicated less preference for programming related to teacher training, engineering, and electronics.

Sixty-two per cent indicated that 'interactivity' as a necessary programme feature. Phone in programs and panel discussions were the most-commonly suggested forms of interactivity cited by respondents.

In terms of the actual duration of Gyan Vani programming content, one-hour long time slots were preferred by 30 per cent of those surveyed. Twenty-six per cent indicated a preference for halfhour programming. Eleven per cent indicated a preference of programming ranging between half to one hour long. Programming of shorter duration (e.g., 15 to 30 minutes) was generally not favoured. These findings suggest that the majority of Gyan Vani's programme content should be one hour in length. Nonetheless, to address other audiences listening preferences, programmes of differing lengths should be broadcast during other time slots that match and maximize that particular audience segment's needs and attention. 
Chandar \& Sharma Bridges to Effective Learning through Radio

\section{Other Suggestions Given by Respondents:}

- Feedback on Gyan Vani programming should be solicited via letters, telephone calls, and email

- $\quad$ Some suggested that students be allowed to host presentations and programs; however, most indicated their preference for subject matter experts to anchors and moderate programming

- Some offered this interesting remark: “Don’t label the channel as ‘educational,' because it will put people off."

- Most respondents said that they want to have a copy of Gyan Vani’s programming schedule at least one day in advance

- It was also suggested that small capsules of curriculum information would be beneficial for some listeners

- Specialised vocational skill courses (e.g., construction and tailoring) are preferred over general ones

\section{Conclusion}

About 83 per cent of those surveyed indicated that they were currently consuming print media. Fifty-four per cent listened to radio regularly. Eighty-eight per cent watch television. Overlaps of media consumption are indicated, as many respondents used more than one media. When asked, 44 per cent were not aware of FM radio technology, even though they were radio listeners. When asked about the role radio plays in their daily life, 50 per cent of respondents indicated they received information (e.g., domestic and global events) that influences their lives, whilst 25 per cent indicated they primarily used radio for learning purposes. In general, respondents were clear in providing suggestions for time slotting, duration, format, programming, style, themes, and content. Such inputs suggest educational radio will likely be popular and useful for those living in and around Coimbatore, thus providing a fertile test-ground for educational and broadcast content development.

Equally important, respondents were clear that they did not want advertisements or 'fancy' anchors to host educational broadcasts. Instead, respondents were generally looking towards Gyan Vani programmes to fulfil both personal and defined educational goals (e.g., certified vocational courses, coaching for entrance exams, current information on careers, courses, etc.)

Radio has made a comeback and clearly it influences the lives of people of all ages in many ways. Radio enhances learning and provides information on various issues critical for making daily decisions. It can even be used for entertainment purposes. And because it does not have the visual distractions of television, which requires one's eyes and ears to both be engaged, low-cost educational programming can form an informational/ educational background that can complement household, manual, and academic work. In short, radio can complement more traditional forms of educational delivery. 


\section{References}

Academy for Educational Development. (1979). Paraguay using radio for formal education in rural areas. Academy News 2(2). Washington, D.C.: Clearinghouse on Development Communication.

Academy for Educational Development. (1980). Health Education Radio Dramas, Sri Lanka. Project profiles. Washington, D.C.: Clearinghouse on Development Communication.

Agency for International Development. (1990). Interactive Radio Instruction: Confronting crisis in basic education. (A.I.D. Science and Technology in Development Series).

Washington, DC: Author. ERIC Document No. ED 322894.

All India Radio (n.d.). All India Radio: growth and development website. Retrieved March 31, 2003 from: http://www.air.org.in

Bansal, K., and Choudhary, S. S. (1999) Interactive Radio for Supporting Distance Education: An evaluative study. Indian Journal of Open Learning 8(1), 61 - 71.

Byram, M. and Kidd, R. (1983). A hands-on-approach to popularizing radio learning group campaigns. Convergence 16(4), $14-22$.

Byram, M., Kaute, C., and Matenge, K. (1980). Botswana takes participatory approach to mass media education campaign. Development Communication Report No. 32.

Chaudhary, S. S. (1996). Current Trends, Methods and Technologies in Distance Education for Primary School Teachers. Working paper. Vancouver: Commonwealth of Learning.

Cooke, T., and Romweber, G. (1977). Radio Nutrition Education - Using the advertising techniques to reach rural families: Philippines and Nicaragua. Washington, D.C.: Manoff International.

Couch, L. (1997). Digital and Analog Communication Systems. Upper Saddle River, NJ.: Prentice-Hall. Retrieved March 31, 2003 from: http://www.telecommunications.msu.edu

Dikshit, H. P. (2002). Preface to study: Radio Vision (Multimedia through Digital Radio). In Sreedher, Radio Vision: Multimedia through Digital Radio. UNESCO and IGNOU.

ERT (Educational, Research and Training Unit) (2001). An Overview: Gyan Darshan, Gyan Vani, Interactive Radio Counselling, Electronic Media Production Centre: IGNOU.

Faulder, D. (1984). Learning on Air. Media in Education and Development 7(1), 36 - 39.

Galda, K. (1984). Learning maths by radio. Media in Education and Development 17(1) 40 - 42.

Ginsburg, M. B., and Arias-Goding, B. (1984). Nonformal education and social reproduction/transformation: Educational radio in Mexico. Comparative Education Review 28(3). 116 - 127. 
Gueri M., Jutsun, P., and White, A. (1978). Evaluation of a Breastfeeding Campaign in Trinidad. Bulletin of the Pan American Health Organization 12(2).

IGNOU (2000). Course ES-318: Communication Technology for Distance Education. Post Graduate Diploma in Distance Education programme. New Delhi: IGNOU.

IGNOU (2001). Gyan Vani: The educational FM radio network of India. Publicity material developed by IGNOU, New Delhi.

Jaminson, D., and McAnany, E. (1973). Radio for Education and Development. Beverley Hills CA.: Sage

Karim, Salma, Kama, Mustafa Azad, and Islam, Md. Mayenul (2001). Role of Radio and TV Programmes in Distance Open Learning Systems: A case of Bangladesh Open University. Indian Journal of Open Learning 10(2), 151 - 158.

Kinyanjui, P. E. (1973). Radio/ correspondence courses in Kenya: An evaluation. Educational Broadcasting International 6(4), 180 - 187.

Long, T. (1984). Broadcasting for Rural Development. Media in Education and Development 17(1), 17 - 19.

McIsaac M., and Gunawardena, C. (1996). Distance education. In D. H. Jonassen (Ed.) Handbook of research for educational communications and technology (p. 403-447). New York: Simon \& Schuster Macmillan.

Muhlmann de Masoner, L., Masoner, P. H., and Bernal, H. (1982). An experiment in radiophonic education: Accion Cultural Popular. Prospects 12(3), 365 - 374.

Muller, J. (1985). Radio for Literacy. A Reader on the Use of Radio in Literacy Programmes. Bonn, Germany: German Foundation for International Development. ERIC Document No. ED 265 372. Cited at All India Radio: growth and development. Retrieved March 31, 2003 from: http://www.air.org.in

Nwaerondu, N. G., and Thompson, G. (1987). The Use of Educational Radio in Developing Countries: Lessons from the Past. Journal of Distance Education 2(2), 43 - 54.

Ouane, A. (1982). Rural newspapers and radio for post-literacy in Mali. Prospects 12(2), 243 253.

Park, H. (1967). Use and relative effectiveness of various channels of communications in the development of the Korean Family Planning Programme. In Economic Commission for Asia and the Far East (ECAFE). Report of the working group on communications aspects of family planning programmes and selected papers, Singapore, September 5-15, 1967. (Population Studies Series, No.3). Bangkok: United Nations, ECAFE.

Ray, H. (1978). The Basic Village Education Project: Guatemala. Washington, D.C.: Academy for Educational Development. 
Saettler, P. (1990). The evolution of American educational technology. Distance-Educatior.com. Retrieved March 31, 2003 from: http://www.distance-educator.com/de_intro.htm

Satyanarayana, P., and Sesharatnam, C. (2000). Distance Education: What? Why? How? Hyderabad: Booklinks Corporation:

Sharma, R. C. (2002a). Interactive Radio Counselling in Distance Education. University News 40(10), $8-11$.

Sharma, R. C. (2002b). Gyan Vani: The Educational FM Radio Network of India. International Review of Research in Open and Distance Learning, 2(2). News from Asia. Retrieved March 31, 2003: http://www.irrodl.org/content/v2.2/field.html

Shears, A. E. (1984). Development of management courses for the agriculture sector in Nigeria. Programmed Learning and Educational Technology, 21(2), 88 - 94.

Sreedher, R. (2002). Radio Vision: Multimedia through digital radio. UNESCO and IGNOU.

Sukumar, B. (2001). IGNOU Interactive Radio Counselling: A study. Indian Journal of Open Learning, 10(1), 80 - 92.

Times News Network (2003). Radio Mirchi is Mumbai's No. 1, shows survey. The Times of India, March 28, p. 8.

Tripp, S., and Roby, W. (1996). Auditory presentations in language laboratories. In D. H. Jonassen (Ed.) Handbook of research for educational communications and technology (p. 821- 850). New York: Simon \& Schuster Macmillan.

Vyas, R. V., Sharma, R. C., and Kumar, A. (2002). Educational Radio in India. Turkish Online Journal of Distance Education 3(3). Retrieved March 31, 2003 from:

http://tojde.anadolu.edu.tr/tojde7/articles/educationalradio.htm

White, R. (1976). An alternative pattern of basic education: Radio Santa Maria. Paris: UNESCO.

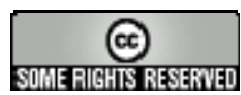

